\title{
On the Opportunities of the Soundscape Approach to Revitalise Acoustics Training in Undergraduate Architectural Courses
}

\author{
Jieling Xiao ${ }^{1, * \mathbb{D}}$, Francesco Aletta ${ }^{2} \mathbb{D}$ and Islah Ali-Maclachlan ${ }^{3}$ \\ 1 School of Architecture and Design, Birmingham City University, Birmingham B4 7BD, UK \\ 2 Institute for Environmental Design and Engineering, University College London, London WC1H 0NN, UK; \\ f.aletta@ucl.ac.uk \\ 3 School of Computing and Digital Technology, Birmingham City University, Birmingham B4 7BD, UK; \\ Islah.ali-maclachlan@bcu.ac.uk \\ * Correspondence: jieling.xiao@bcu.ac.uk; Tel.: +44-0121-331-5984
}

check for updates

Citation: Xiao, J.; Aletta, F.;

Ali-Maclachlan, I. On the

Opportunities of the Soundscape Approach to Revitalise Acoustics Training in Undergraduate Architectural Courses. Sustainability 2022, 14, 1957. https://doi.org/ $10.3390 /$ su14041957

Academic Editors: Jooyoung Hong and Bhan Lam

Received: 11 January 2022

Accepted: 4 February 2022

Published: 9 February 2022

Publisher's Note: MDPI stays neutral with regard to jurisdictional claims in published maps and institutional affiliations.

Copyright: (C) 2022 by the authors. Licensee MDPI, Basel, Switzerland. This article is an open access article distributed under the terms and conditions of the Creative Commons Attribution (CC BY) license (https:// creativecommons.org/licenses/by/ $4.0 /)$.

\begin{abstract}
Soundscape research has been gaining prominence in studies on the built environment. The soundscape concept is defined as the acoustic environment as perceived and/or understood by a person in context. Compared with traditional building acoustics, the soundscape concept brings interesting perspectives - but also challenges_-for undergraduate architectural curricula, where it tries to strike a balance between qualitative and quantitative methodologies, a theoretical approach that in the context of soundscape studies it is often referred to as 'triangulation'. Starting from realworld higher education courses, the aim of this paper is to examine how the soundscape approach can be integrated into teaching building acoustics at the undergraduate level in architectural courses. Methods such as soundwalks, acoustic measurements, and computational simulations that are commonly used in soundscape research are introduced in educational projects as tools for students to experience, analyse, and articulate the narrative around the sound environment to inform their design concepts and details.
\end{abstract}

Keywords: soundscape; acoustics; architectural education; pedagogy; architectural practice

\section{Introduction}

In architectural disciplines, there is an increased interest in pursuing environmental quality and human comfort. Research and concepts such as liveable cities, healthy cities are all calling for design revolutions to improve well-being and quality of life for people and communities. Unlike daylight and thermal comfort, acoustic design has historically been marginalised and considered as an engineering element mostly meant for acousticians, i.e., mostly outside the remit of 'designers'. This is also often true within the framework of architectural education, where essentials of room acoustics are only taught in 'some architectural schools with an engineering focus and embedded in either building physics or architecture technology courses' [1]. Taking the UK as an example, the accreditation document of architectural courses has not given specific requirements on the acoustics training aspect. It is only mentioned in GC9, together with the other environmental elements that graduates need to know the principles associated with designing acoustic environments [2]. However, national institutions and agencies have published building regulations specific to the acoustic environment-BS 8233:2014 Guidance on sound insulation and noise reduction for buildings. For schools and hospitals, further design guidance has been published, such as the Building Bulletin 93: Acoustic design of schools: performance standards and Health Technical Memorandum 08-01: Acoustics. The benchmarks of acoustic parameters in these regulatory documents are critical to set acoustic design objectives and assess the acoustic qualities in the design process. These professional requirements demand an active approach to acoustic design education in architectural disciplines. 
The soundscape concept has offered an alternative approach to exploring and designing acoustic environments, linking the science domain to art and humanities. Defined by ISO 12913-1:2014, a soundscape is the 'acoustic environment as experienced and/or understood by a person in a context' [3]. The concept originated from Schafer's exploration into the ecology of the sonic environment and the relationship between people and sounds in the built environment [4]. It shifted the focus from noise pollution to a narrative about sonic environments across disciplines_art, architecture, music, geography, and planning. One of the key questions frequently asked about soundscape is its difference from the acoustic environment [5]. The acoustic environment can be considered as the physical phenomenon, whilst soundscape is a perceptual outcome related to a given acoustic environment, where the human auditory experiences (via listening) and individuals' sociocultural context play important roles. It emphasises the perceived qualities of the acoustic environment and the context of places. Soundscape research has developed from standardising the definition and assessment to specifying the perceptual indicators. Soundscape research considers sounds not just as an environmental element but also as a socio-cultural component and even cultural heritage.

Existing soundscape research has offered frameworks that can be referred to for acoustic design and education alternatively. Brown [6] suggests defining the acoustic objectives is key in the planning and design of urban soundscape. The wanted and unwanted sounds can be dealt with four principles - separate, remove, mask, and enhance. Shafer introduces a typology of sounds in the built environment to understand the sonic characteristics of places-ambient sounds, sound marks, keynote sounds, and signal sounds. Aletta et al. [7] summarise three approaches to investigate acoustic environment with different methods and tools: (1) in situ experiences via behavioural observations and soundwalks; (2) simulation and reproduction via laboratory experiments with subjective evaluations and physiological measurements; (3) recalled memories via narratives. Educational modules of soundscape could be considered from four areas: concepts and terms, measurements, analysis, and evaluation.

Educators in architectural and design disciplines have started to experiment with these soundscape frameworks and data collection methods, to teach about acoustic environments, but challenges remain to implement these theoretical frameworks into teaching. Situated listening through soundwalks has been used as a primary method to engage students with the acoustic environment. As Harvey [8] (p.136) suggests:

'While design students are visually astute, their listening skills and general awareness of the acoustic environment is often underdeveloped. However, their ability to imagine spaces in three dimensions and consider the motion of an observer through space is an important skill that can be harnessed when researching actual, or designing a virtual soundscape.'

Sound diaries, recordings, and maps to document the aural experiences are commonly used along with soundwalks. The measurement of sound pressure levels and the basics of reverberation time and acoustic materials are useful to the description of the acoustic environments. For design studios, visualising the acoustic environment and developing a design strategy to respond to the sonic features is critical. For research purposes, it is essential to teach step by step from concepts and terms to measurements and analysis that enables the scientific interpretation of analysed data [9]. A few challenges are identified: (1) the engagement with the digital tools to simulate the acoustic environments and ways to represent acoustic design ideas [10]; (2) the lack of laboratory settings for experiments also limits the pedagogical integration; (3) the communication of the complexity of the subject and the scientific concepts involved.

Being aware of these challenges, this paper aims to determine to what extent we should integrate soundscape research in undergraduate architectural education. Taking the reflective practice approach, we compared the differences in the teaching and learning process between sound engineering students and architectural design students through 
four educational projects delivered between 2015 and 2020 at different higher education institutions in the UK.

\section{Methodological Considerations and Case Studies}

\subsection{The Reflective Practice}

The reflective practice approach is often used in pedagogical studies in higher education. Schön [11] suggests that reflections on the actions taken in professional practice are inquiries into the epistemology of practice. It is also a way of better understanding the 'intuitive' knowledge involved in actions, as well as producing new insights into further actions. Reflection initiates conversations on the failures and successes of past experiences, in situ observations, and decision-making processes [12,13]. Mezirow [14] argues that reflection should critically question the content and process involved in the experience. Plack and Greenberg [15] suggest using questions to facilitate critical thinking in a reflective inquiry.

This study can be described in two stages: In 2019, a preliminary inquiry was conducted through a focus group, with all authors reflecting on three undergraduate educational projects (projects 1-3), delivered with students from sound engineering and architecture. Project 4 (2020) details a new joint educational project for third-year architectural undergraduate students; a follow-up inquiry through a focus group discussion to reflect on the delivery of the design educational project was conducted in 2021. The focus group discussion is used as the method to collect data on the reflections for both stages. During the discussion, a few questions were asked: What was the objective of using the soundscape approach in the project? To what extent the soundscape concepts and theories were delivered? How was the learning transformed from acoustics to soundscape? What challenges were experienced? Key themes were summarised from the conversations, discussed in the context of scientific literature, and analysed in light of students' feedback from the module reviews.

\subsection{The Soundscape Educational Projects}

\subsubsection{Project 1-Implementing Waterscape Sound to Mask Traffic Noise}

Waterscapes are suggested to be effective in masking traffic noise in urban spaces [16]. For acousticians, it is essential to understand the underlying scientific principles to implement this into future projects. Working with a Level 6 BSc Sound Engineering and Production student from Birmingham City University, the project involved analysing and redesigning the waterscape sound spectrum at Wisley Gardens and Cottage Gardens to mask the traffic noise more effectively. Measurements and listening tests [17] were introduced to assess and verify the results (Figure 1). The pairing of water feature and traffic noise follows the method outlined in You et al. [18], in which traffic noise at two constant SPLs of 55 and $75 \mathrm{dBA}\left(\mathrm{L}_{\mathrm{Aeq}, 20 \mathrm{~s}}\right)$ and water sounds $\left(\mathrm{L}_{\mathrm{Aeq}, 20 \mathrm{~s}}\right)$ were presented at various levels from -6 to $+6 \mathrm{~dB}$ in five $3-\mathrm{dB}$ steps. In our experiment, participants selected the minimum level of water feature sound that they felt adequately masked the corresponding road traffic noise. A video of the water feature was played concurrently, allowing participants to experience visual as well as auditory stimuli. The tests were set up with a constant level of traffic noise and a water feature sound that could start at $-\infty \mathrm{dB}$ or $+12 \mathrm{~dB}$, allowing any bias that came from masking sound gradually increasing or decreasing to be explored. Fader levels for each participant were logged, and a box-and-whisker plot shows the effectiveness of each water feature. Spectrogram plots comparing the traffic and water feature spectrums were also consulted to understand frequencies at which the traffic noise might have more impact. 

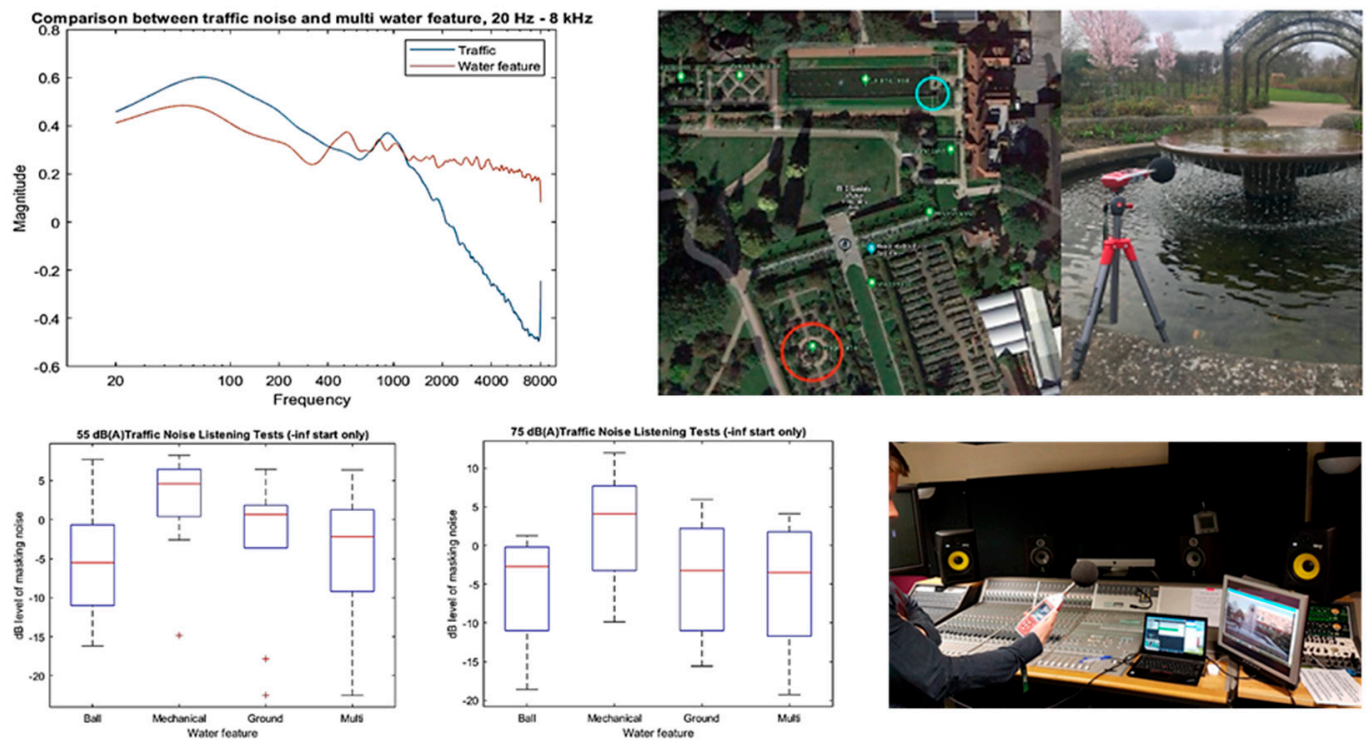

Figure 1. Onsite acoustic measurement and listening test for modifications of waterscapes at Wiley Gardens and Cottage Gardens (Visual credits: Ali-MacLachlan and Rowland, 2019).

\subsubsection{Project 2 - Conceptual Soundscape Design for the Valley Gardens, Brighton and Hove}

Perceptual qualities of the acoustic environments can be measured via soundscape descriptors. One of the well-established soundscape models is the framework developed by Axelsson et al. [19]. However, interpreting these descriptors and linking them to the design language is challenging. This workshop was a one-week learning session with Level 6 architectural students from the School of Architecture at the University of Sheffield. Students were asked to work in small groups using binaural recordings collected on a designed walking route by a team of researchers in the context of the SONORUS project [20]. They analysed the available research materials and datasets to identify problems at the site, which then led to a conceptual design proposal presented in sketches. A lecture was given on basic soundscape and acoustic concepts, explaining the soundscape descriptors, design principles, and soundwalk methods. Students focused on the sound sources to develop actions to change soundscape characteristics. The design responses were derived from a number of precedents and followed the approach of sound masking and function separation. However, at this stage, and due to time constraints, proposals were purely conceptual rather than fully designed and engineered (Figure 2).

\subsubsection{Project 3-Assess and Improve the Acoustic Environment in Libraries}

Loudness is an important perceptual factor in soundscape assessment, particularly in spaces such as libraries. However, the design of public library spaces in the contemporary context has challenged the traditional premises to be silent [21]. A 10-week technical investigation project with Level 6 architectural students from Birmingham School of Architecture and Design aimed to assess and improve the acoustic design for the Library of Birmingham. Students conducted soundwalks in groups and subjective evaluations of the perceived loudness via binaural listening with measurements of $\mathrm{L}_{\text {Aeq }}$ through a mobile app called the I-Audio tool [22] at different stops. Focus group discussions were conducted to analyse the group data and propose strategies to improve areas where the perceived loudness was inappropriate to the library layout and function. They were asked to render or visualise their interventions and test how effective the proposed solutions were using a freely available acoustic simulation software I-Simpa [23] (Figure 3). In addition to the lectures on soundscape and acoustics basics, students were offered workshops on acoustic simulation software. The visual observations have been a key driver in their interpretation of the data and relate to the spatial planning of the library. However, for the various data forms collected, some students were struggling to identify their focuses to produce design 
responses. The most common responses were to deal with areas affected by the escalator noise, using sound baffles and absorption materials tested in I-Simpa.

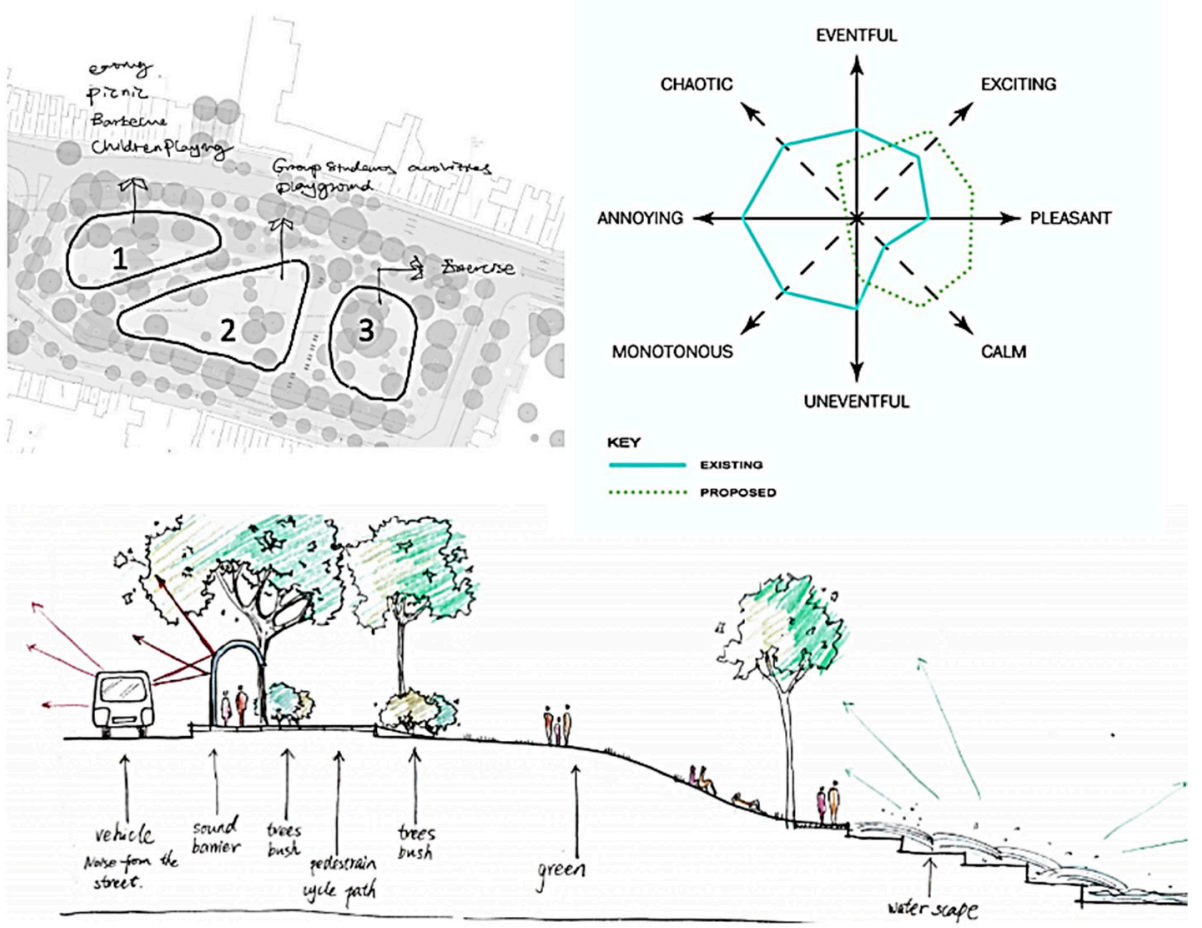

Figure 2. Soundscape investigation and conceptual design ideas for Valley Gardens (Visual credits: Huang, Ibrahim, Penha, Xu, and Zhang, 2015).
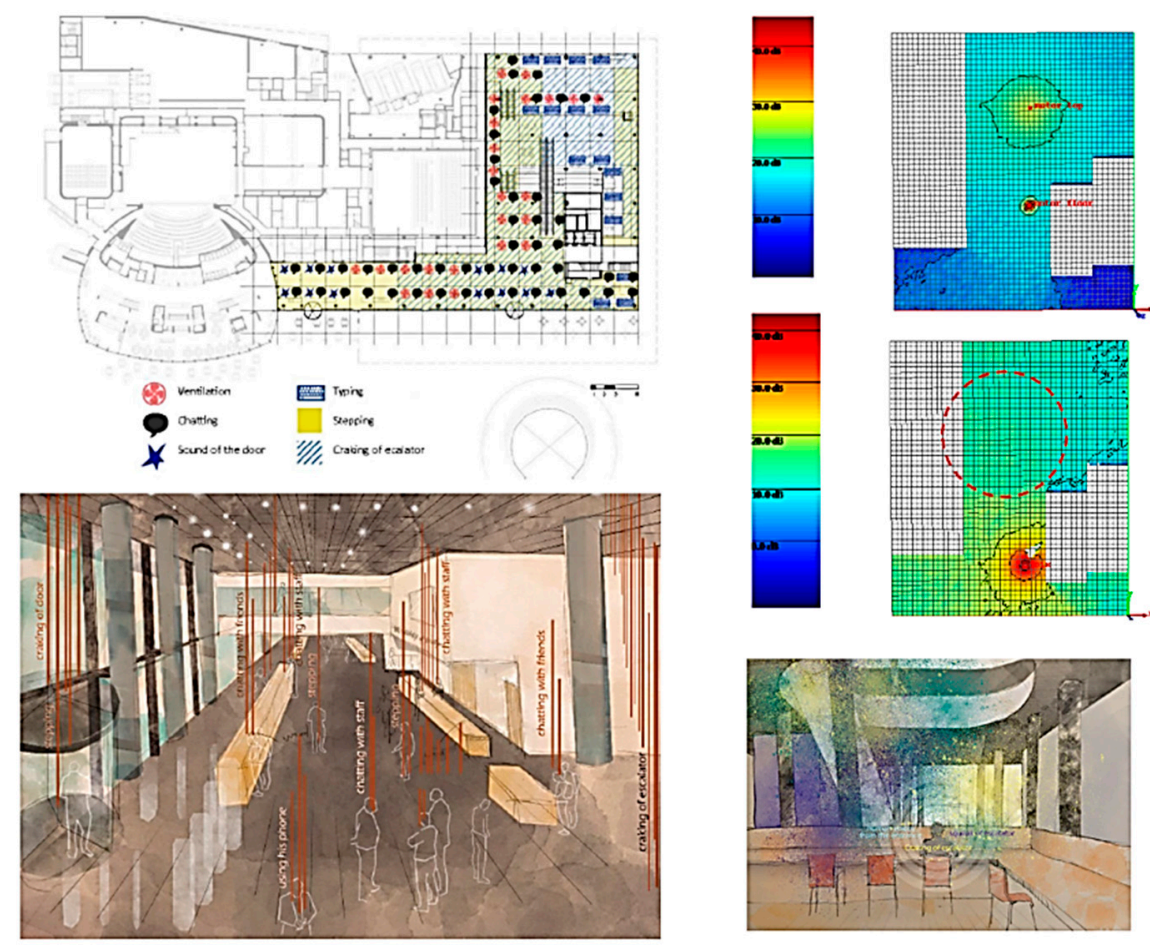

Figure 3. Sound mapping and I-Simpa simulation of sound pressure levels in the Library of Birmingham with or without the escalator noise (visual credits: Chloe and James, 2016). 


\subsubsection{Project 4-Understand the Acoustic Spirituality in Worship Spaces}

Acoustic environments in worship spaces are considered important to spatial qualities [24]. In particular, reverberation is critical in worship spaces, where the geometry and volume are unique to the design. Working with Level 6 architectural students from Birmingham School of Architecture and Design, this project asked how geometry and materiality influence acoustic spirituality in such spaces via case studies. Due to COVID-19, students were asked to conduct desk research about the given case and conduct simulations in I-Simpa (Figure 4). In this six-week project, lectures on the acoustic basics and workshops on the simulation software were given. Although when interpreting the data, students relied on the visual representations from the software, they could understand and explain the reverberation time $\left(\mathrm{T}_{30}\right)$ from the simulation results in relation to the materials and geometries of buildings. Based on the results, they were also able to make proposals for repurposing such buildings in the future taking a sustainable approach.

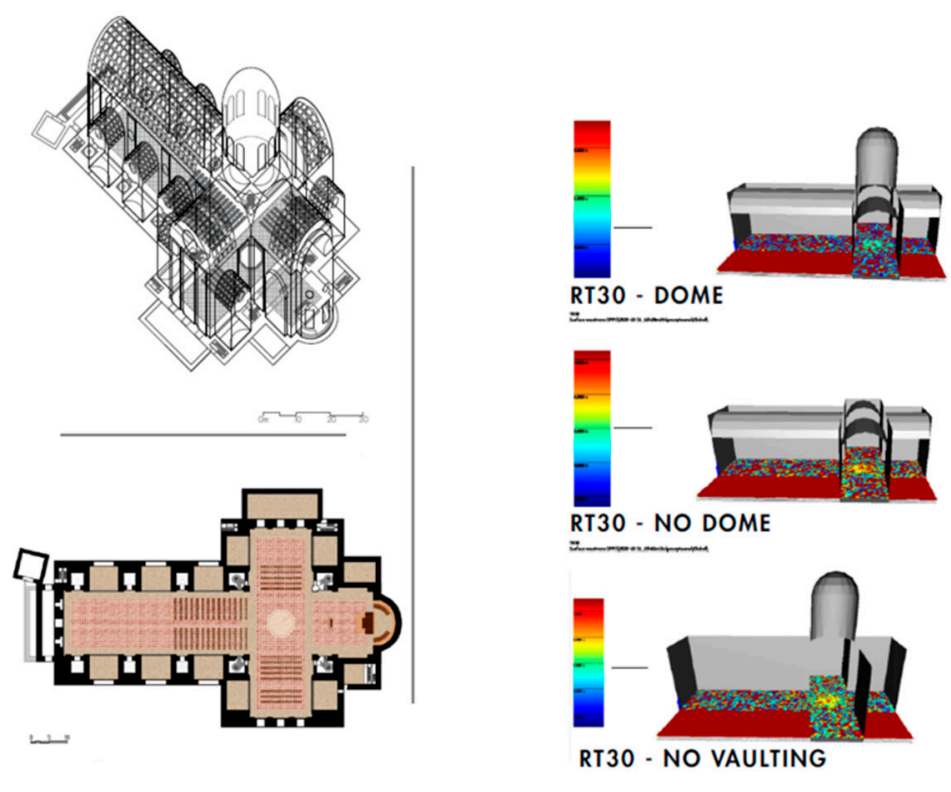

Figure 4. Investigation of the impact of the dome and vaulting on the reverberation time in St Andrea Cathedral via I-Simpa simulation (Visual credits: Emily, Georgia, Amie-Jo, and Fraz, 2020).

\section{Lessons Learned and Future Steps}

\subsection{Soundscape as an Icebreaker, Not a Framework}

The soundscape concept emphasises the ecology between humans and sounds in the environment. It requires further thinking about the space or the environment beyond its physical entities, to seek emotive inquiries and sociocultural responses. Students feel comfortable to engage with the soundscape concept because it deals with human experiences and does not limit the way of looking at the acoustic environments. The soundscape concept works well as a catalyst for alternative angles to explore sites and design concepts. For example, Project 2, as an add-on short project to the design module, was successful in enabling students to transform their onsite perceptions to soundscape design ideas, and to create positive sonic experiences for the site. To what extent do students learn about acoustics? The ways in which sound propagation is represented in sketches may look naïve, and therefore, further training about acoustic materials and simulations is often needed to provide a meaningful and realistic design proposal. However, the knowledge provided is sufficient to raise awareness about acoustic environments in general. This kind of short projects-using the soundscape concept to provoke consideration of the environment from the acoustics dimension-works in situations that only require an overall understanding and the issues involved. Sound mapping, narratives of experiences, recordings of sounds, and sound pressure levels, are all useful tools for such educational purposes. 
Soundscape introduces the links between acoustic environments and sociology, culture, and history of places through individual experiences and thinking. This offers opportunities for educators to bridge the science of acoustics to the design language and concepts with which architectural students are familiar. However, the implementation of the psychoacoustic parameters as a language to describe the felt quality of acoustic environments has pros and cons. We organised the focus group discussions to ensure the understanding of each parameter is the same. This is a calibration process to ensure that students can work as a group to discuss the subjective data collected. However, when it comes to subjective evaluations and interpretation of data, students found it difficult. For example, one student from Project 3 questioned:

'I can work with the measured data and simulation. But I don't know how to use the subjective data. If the subjective data collected cannot be used to generalise perceptions of the acoustic environments, how much shall we refer to it when analysing the data and define our design objectives? How can we predict perceptions?'

Although soundscape works as an icebreaker to the introduction to the building acoustics, we should be clear about the difference between the two. The primary focus should still be understanding the impact of architectural design (e.g., geometry, materials, scale) on the acoustic environments. As educators, it is a challenge to be clear about why we use the soundscape concept in our teaching, and how much we are including soundscape-related research questions. The four projects all started with introducing the soundscape concept whilst taking different approaches to using existing research and frameworks in the project design and teaching. Research findings on specific architectural or urban elements such as the waterscape sound can mask traffic noise and contribute to well-being can be used to push for detailed acoustic design solutions in educational projects. For example, the urban soundscape design research conducted in the SONORUS Project [25] offers design guidance to deal with urban traffic noise. Tasks to repeat data collection and analysis are useful at the start of the project to situate students in the learning environment. Theoretical soundscape frameworks such as the perceptual model used in Project 2 and the soundscape model in ISO standards are sometimes difficult for students to engage with, without further interpretations and examples. Educators need to transform the theoretical findings to practical implementations to site explorations, communications, or design approaches with examples. Comparing Projects 2 and 3, looking at one or two parameters from the framework might be easier to set the learning tasks and identify the corresponding acoustic concepts.

\subsection{The Mindset Matters}

Comparing Project 1 with the other projects, we realised that architectural students are more interested in spatial geometry, visual representations, and acoustic materials rather than acoustic specifications, which the sound engineering students preferred instead. In Project 4, we used an architectural theoretical concept-spirituality-to link acoustic concepts to the design and artistic thinking of worship spaces. Listening to the choral singing in churches and chanting in mosques via video clips on YouTube, students were motivated to describe their perceptions and explore how acoustics works to achieve emotive quality. The difference of learning interests in acoustics between sound engineering students and architectural students indicates a design-concept-oriented approach to teaching acoustics for architectural disciplines. Apart from the typology of sounds by Schafer [4], interesting concepts from soundscape research can also link to spatial thinking and design. For example, Augoyard and Torgue [26] have constructed a list of sonic effects from everyday experiences of the acoustics environments to understand characteristics of the perceived acoustic environments. Concepts they put forward such as 'sound door' and 'sound lock' can be further explored.

Soundscape research methods and acoustic concepts should be intertwined in teaching and learning. Bloom introduces the idea that the cognitive process of learning at undergraduate level moves from understanding and application to analysis and evaluation [27]. 
Integrating building acoustics with architectural education, an aural scale with different levels of learning should also be created to build progressive learning of the subject. An architectural design process often involves site inventory, conceptual design, visualisation, and technical resolution. Milo [1] proposes that acoustic design education should be informed by both soundscape and architectural acoustics involving listening practices, designing technical solutions, and critical reflections on design practices. Truax [28] emphasises that acoustic design cannot be considered separately from other environmental elements and should be embedded into the environmental design as a system of interactions with others.

\subsection{The Aural Scale}

Defining the educational objectives of acoustic design at different levels is critical to guide the content and methods of teaching acoustics for architectural disciplines. Brown [6] suggested that setting acoustic objectives is essential to any soundscape planning process. Noting the difficulty of managing subjectivity, Brown specified the objectives should be acoustically clear and achievable. However, the perceptual layer of information is associated with the archetype/perceiver/user of the space to set the architectural design goals. We would like to introduce the aural scale a set of acoustics-related learning dimensions responding to the design process and objectives, based on the reflections of our teaching practices (Figure 5).

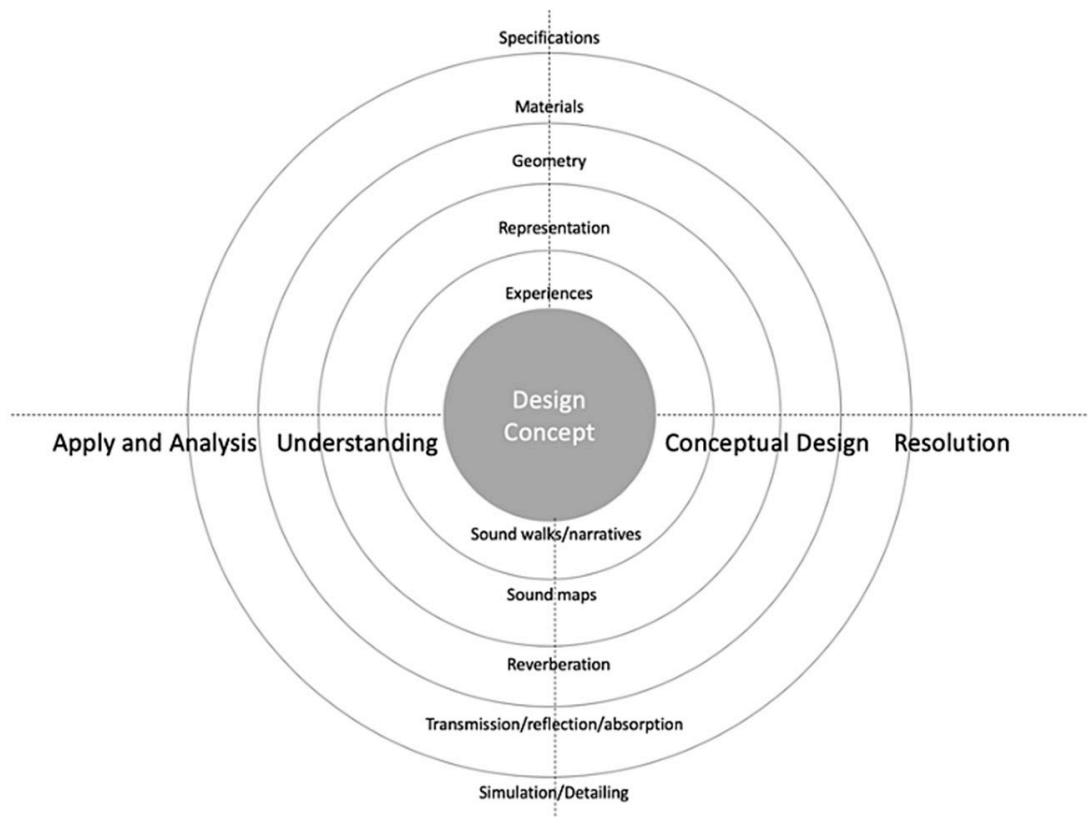

Figure 5. A design-concept-centred aural scale for engaging in soundscape practice within architectural disciplines.

The focus of acoustics design education in Level 4 modules should be on the understanding of sound propagation and the awareness of the acoustic environments engaging with listening. Short projects with soundwalks and mapping to understand the site conditions such as Project 1 will be useful. Soundscape can be introduced as a theoretical concept to make students think about sonic experiences and how sound works in spaces. Students can easily engage with the introductory acoustic knowledge on the definition of sound, sound propagation, sound pressure levels, and human hearing. For Level 5, it will be useful to introduce associated regulations and benchmarks of specific functional spaces aligning with the design studio projects such as theatres and concert halls, housing, hospitals, and offices. The acoustic concepts such as frequency, reverberation, sound absorption, transmission, and reflection should be taught. The focus at this stage for acoustics 
design is technical solutions enabling students to identify acoustic problems and apply basic technical strategies from examples of common practices on technical details that reduce passage sounds and different types of acoustic materials.

Synthesis of both qualitative and quantitative knowledge of acoustic environments is the educational objective of acoustic design at Level 6. Specific soundscape concepts or acoustic design aspects can be explored with simulation and narrative inquiries, to enable students to identify acoustic problems and test proposed acoustic design solutions. We arranged two half-day workshops in Projects 3 and 4 to train students to use I-Simpa. Most of them could manage to use the software following the workshop steps. However, the software can only handle relatively simple geometrical configurations, which limits what students can accomplish with it (Figure 4). Compared with the simulated data, students were more excited by the visualised acoustic contour maps and animations. The simulation tool in this sense can be introduced as a communication tool, as well as an analytical tool. The challenge will be the training of the software and timescale. One opportunity we see is a collaborative education project with sound engineering students.

Another challenge faced by educators is the lack of comprehensive and designorientated teaching materials. One of the most commonly used handbooks of architectural acoustics is the one by Long [29]. It is scientifically oriented, with limited practical guidance. The later publication by Ermann [30] has relatively more visual illustration and construction details. However, these are not giving enough precedents and design context for readers to better understand acoustics from the design perspective. The most recent book by Patel [31] offers a good range of case studies and a summary of acoustic design principles of each type of buildings with rich visual information. However, the analysis of precedents is descriptive and generic and, therefore, has not provided in-depth information on construction details, materials, and their acoustic properties. The introduction to different innovative acoustic materials and projects by Adams [32] is also a visually engaged reference that needs further interpretation on the construction details. These books offer a structure for acoustic design education whilst a balance between the conceptual design ideas and acoustic engineering in the teaching practice needs to be managed to respond to the learning levels and educational objectives.

In summary, soundscape studies started with a focus on outdoor settings, but the related concepts are attractive for students working in design-related disciplines of the built environment in general, and the most recent research trends indeed show the perceptual approach promoted by the soundscape community to emerge as a theme also in indoor contexts [33-35]. A general gap between academia and practice in soundscape studies has been already acknowledged in the past [36]. To address this gap, higher education professionals will have to gather such empirical evidence and theoretical models emerging from scientific literature and translate it into suitable learning and teaching materials for undergraduate students with different training frameworks and backgrounds.

Author Contributions: Conceptualisation, J.X., F.A. and I.A.-M.; methodology, J.X.; data curation and analysis, J.X.; writing - original draft preparation, J.X.; writing-review and editing, F.A. and I.A.-M.; visualisation, J.X., F.A. and I.A.-M. All authors have read and agreed to the published version of the manuscript.

Funding: This research received no external funding.

Institutional Review Board Statement: The relevant part of this study was conducted according to the guidelines of the Declaration of Helsinki, and approved by the Ethics Committee of the School of Architecture of the University of Sheffield (Reference Number 006881, 30 November 2015).

Informed Consent Statement: Informed consent was obtained from all subjects involved in the study.

Data Availability Statement: Not applicable.

Acknowledgments: Thanks to the students for providing visuals from their projects to be included in the paper. Part of the paper was presented at the Amps conference for Teaching-Learning-Research: Design and Environments, 2-4 December, Manchester, 2020. 
Conflicts of Interest: The authors declare no conflict of interest.

\section{References}

1. Milo, A. The acoustic designer: Joining soundscape and architectural acoustics in architectural design education. Build. Acoust. 2019, 27, 83-112. [CrossRef]

2. Royal Institute of British Architects. Procedures for Validation and Validation Criteria for UK and International Courses and Examination in Architecture; Royal Institute of British Architects: London, UK, 2011; p. 61.

3. ISO 12913-1: 2014; Acoustics-Soundscape-Part 1: Definition and Conceptual Framework. International Organization for Standardization: Geneva, Switzerland, 2014.

4. Schafer, R.M. The Soundscape: Our Sonic Environment and the Tuning of the World; Simon and Schuster: New York, NY, USA, 1993; pp. 3-12.

5. Kang, J.; Aletta, F.; Gjestland, T.T.; Brown, L.A.; Botteldooren, D.; Schulte-Fortkamp, B.; Lercher, P.; van Kamp, I.; Genuit, K.; Fiebig, A.; et al. Ten questions on the soundscapes of the built environment. Build. Environ. 2016, 108, 284-294. [CrossRef]

6. Brown, A.L. A review of progress in soundscapes and an approach to soundscape planning. Int. J. Acoust. Vib. 2012, 17, 73-81. [CrossRef]

7. Aletta, F.; Kang, J.; Axelsson, Ö. Soundscape descriptors and a conceptual framework for developing predictive soundscape models. Landsc. Urban Plan. 2016, 149, 65-74. [CrossRef]

8. Harvey, L. The Aural Eye: Soundscape Practice and Pedagogy in Design Education. Idea J. 2005, 6, 127-138. [CrossRef]

9. Fiebig, A.; Acloque, V.; Basturk, S.; Di Gabriele, M.; Horvat, M.; Masullo, M.; Pieren, R.; Voigt, K.S.; Yang, M.; Genuit, K.; et al. Education in Soundscape-A seminar with young scientists in the COST Short Term Scientific Mission Soundscape-Measurement, Analysis, Evaluation. In Proceedings of the 20th International Congress on Acoustics, Sydney, Australia, $23-27$ August 2010.

10. Fowler, M.D. Soundscape as a design strategy for landscape architectural praxis. Des. Stud. 2013, 34, 111-128. [CrossRef]

11. Schön, D.A. The Reflective Practitioner: How Professionals Think in Action; Basic Books: New York, NY, USA, 1982.

12. Dewey, J. Experience and Education; Simon \& Schuster: New York, NY, USA, 1938.

13. Kolb, D. Experiential Learning: Experience as the Source of Learning and Development; Prentice-Hall, Inc.: Englewood Cliffs, NJ, USA, 1984.

14. Mezirow, J.A. Fostering Critical Reflection in Adulthood: A Guide to Trans-formative and Emancipatory Learning; Jossey-Bass: San Francisco, CA, USA, 1990.

15. Plack, M.M.; Greenberg, L. The reflective practitioner: Reaching for excellence in practice. Pediatrics 2005, 116, 1546-1552. [CrossRef] [PubMed]

16. Kang, J.; Hao, Y. Waterscape and Soundscape in Sheffield. Available online: http://www.soundscape-cost.org/documents / Brighton_2011/COST_Brighton_Waterscape_sheffield_JKang.pdf (accessed on 10 January 2022).

17. Watts, G.R.; Pheasant, R.J.; Horoshenkov, K.V.; Ragonesi, L. Measurement and subjective assessment of water generated sounds. Acta Acust. United Acust. 2009, 95, 1032-1039. [CrossRef]

18. You, J.; Lee, P.J.; Jeon, J.Y. Evaluating Water Sounds to Improve the Soundscape of Urban Areas Affected by Traffic Noise. Noise Control Eng. J. 2010, 58, 477-483. [CrossRef]

19. Axelsson, Ö.; Nilsson, M.E.; Berglund, B. A principal components model of soundscape perception. J. Acoust. Soc. Am. 2010, 128, 2836-2846. [CrossRef] [PubMed]

20. Alves, S.; Estévez-Mauriz, L.; Aletta, F.; Echevarria-Sanchez, G.M.; Puyana Romero, V. Towards the integration of urban sound planning in urban development processes: The study of four test sites within the SONORUS project. Noise Mapp. 2015, 2, 57-85. [CrossRef]

21. Mattern, S. Resonant texts: Sounds of the American public library. Senses Soc. 2007, 2, 277-302. [CrossRef]

22. I-Audio Tool: A Mobile App That Measures Reverberation Time, Sound Pressure Level. Available online: https://appadvice. com/game/app/iaudiotool/580740399 (accessed on 27 January 2022).

23. Picaut, J.; Fortin, N. I-Simpa, a graphical user interface devoted to host 3D sound propagation numerical codes. Acoustics 2012, 1-8. Available online: https://www.researchgate.net/publication/281417937_I-Simpa_a_graphical_user_interface_devoted_ to_host_3D_sound_propagation_numerical_codes (accessed on 10 January 2022).

24. Kleiner, M.; Klepper, D.L.; Torres, R.R. Worship Space Acoustics; J. Ross Publishing: Fort Lauderdale, FL, USA, 2010 ; pp. 203-269.

25. Alves, S.; Estévez-Mauriz, L. Applied urban sound planning. In Urban Sound Planning: The Sonorus Project; Kropp, W., Forssén, J., Estévez-Mauriz, L., Eds.; Chalmers University of Technology Publishing: Gothenburg, Sweden, 2016; pp. 69-114.

26. Augoyard, J.F. Sonic Experience: A guide to Everyday Sounds; McGill-Queen's Press: Montreal, QC, Canada, 2006 ; p. 33.

27. Bloom's Taxonomy: A Taxonomy for Teaching, Learning and Assessment. Available online: https://www.bloomstaxonomy.net/ (accessed on 9 January 2022).

28. Truax, B. Acoustic Communication; Greenwood Publishing Group: Westport, CT, USA, 2001.

29. Long, M. Architectural Acoustics; Elsevier: Amsterdam, The Netherlands, 2005.

30. Ermann, M. Architectural Acoustics Illustrated; John Wiley \& Sons: Chichester, UK, 2015.

31. Patel, R. Architectural Acoustics: A Guide to Integrated Thinking; Routledge: London, UK, 2020.

32. Adams, T. Sound Materials: A Compendium of Sound Absorbing Materials for Architecture and Design; Frame Publishers: Amsterdam, The Netherlands, 2016. 
33. Dokmeci Yorukoglu, P.N.; Kang, J. Analysing sound environment and architectural characteristics of libraries through indoor soundscape framework. Arch. Acoust. 2016, 41, 203-212. [CrossRef]

34. Torresin, S.; Albatici, R.; Aletta, F.; Babich, F.; Oberman, T.; Siboni, S.; Kang, J. Indoor soundscape assessment: A principal components model of acoustic perception in residential buildings. Build. Environ. 2020, 182, 107152. [CrossRef]

35. Torresin, S.; Aletta, F.; Babich, F.; Bourdeau, E.; Harvie-Clark, J.; Kang, J.; Albatici, R. Acoustics for supportive and healthy buildings: Emerging themes on indoor soundscape research. Sustainability 2020, 12, 6054. [CrossRef]

36. Aletta, F.; Xiao, J. What are the current priorities and challenges for (urban) soundscape research? Challenges 2018, 9, 16. [CrossRef] 